\title{
Fındık Kabuklarından Elde Edilmiş Odun Sirkesi’ nin In-Vitro Şartlarında Antifungal Etkisinin Belirlenmesi
}

\author{
İbrahim KOÇ ${ }^{1^{*}}$, Erdal Necip YARDIM ${ }^{2}$, Ali ÇELIK ${ }^{3}$, Mehmet MENDEŞ $^{4}$, \\ Hamit MIRTAGİGGLU ${ }^{5}$, Ayten NAMLI ${ }^{6}$ \\ ${ }^{1}$ Bitlis Eren Üniversitesi, Mühendislik-Mimarlık Fakültesi, Çevre Mühendisliği Bölümü, 13000, Bitlis \\ ${ }^{2}$ Bitlis Eren Üniversitesi Rektörlüğ̈̈̈, 13000, Bitlis \\ ${ }^{3}$ Abant İzzet Baysal Üniversitesi, Ziraat ve Doğa Bilimleri Fakültesi, Bitki Koruma Bölümü, 14000, Bolu \\ ${ }^{4}$ Çanakkale Onsekiz Mart Üniversitesi, Ziraat Fakültesi, Zootekni Bölümü, 17000, Çanakkale \\ ${ }^{5}$ Bitlis Eren Üniversitesi, Fen Edebiyat Fakültesi, İstatistik Bölümü, 13000, Bitlis \\ ${ }^{6}$ Ankara Üniversitesi, Ziraat Fakültesi, Toprak Bilimi ve Bitki Besleme Bölümü, 06030, Ankara
}

\begin{abstract}
Öz
Bu çalışma findık kabuklarından elde edilen odun sirkesi'nin, in-vitro şartlarında Aspergillus niger ve Penicillium digitatum'a karşı antifungal etkisini saptamak amacıyla yapılmıştır. Odun sirkesi’nin $\% 1, \% 3, \% 5, \% 7$ ve \%10 mL'lik konsantrasyonlarının dâhil edildiği Patates Dekstroz Agar (PDA)'a, mikrofungusların 5 mm çapındaki miselyum diskleri inoküle edildikten sonra $24 \pm 1 \mathrm{oC}$ 'de 7 gün boyunca inkübasyona bırakılmıştır. İnkübasyonun sonunda mikrofungusların koloni çapları ölçülmüş ve kontrollere göre odun sirkesinin \% engelleme oranları hesaplanmıştır. Yapılan varyans analizi sonucunda dikkate alınan uygulamalar arasında istatistiksel olarak önemli farkların bulunduğu görülmüştür $(\mathrm{P}=0.000)$. Varyans analizi sonucunda uygulanan Dunnett testi sonucunda ise kontrol grubu ile $\% 1 \mathrm{~mL}$ odun sirkesi hariç, odun sirkesinin diğer dozları arasında istatistiksel olarak önemli farkların bulunduğu görülmüştür. Sonuç olarak; odun sirkesinin küf mantarlarını engellemede kullanılabileceği sonucuna varılmıştır.
\end{abstract}

Anahtar kelimeler: Antifungal, Mikrofungus, Odun sirkesi, İn-vitro.

\section{Determination of Antifungal Effect of Wood Vinegar Obtained from Hazelnut Shells in In-Vitro Conditions}

\begin{abstract}
This study was carried out at in-vitro conditions to determine the antifungal effect of the wood vinegar obtained from hazelnut shells, on Aspergillus niger and Penicillium digitatum microfungi. Potato dextrose agar (PDA) containing concentrations of $1 \%, 3 \%, 5 \%, 7 \%$ and $10 \%$ of the wood vinegar was allowed to incubation for 7 days at $24 \pm 1{ }^{\circ} \mathrm{C}$ after inoculation of $5 \mathrm{~mm}$ diameter mycelium discs of microfungi. At the end of incubation, the colony diameters of the microfungi were measured and the $\%$ inhibition rates of the wood vinegar, were calculated according to the controls. Results of One-way ANOVA showed that there were statistically significant differences among the doses $(\mathrm{P}=0.000)$. Based on the Dunnett's test results, it was determined that the differences between the control group and the other doses of wood vinegar were statistically significant except for the $1 \% \mathrm{~mL}$ wood vinegar dose. As a result; it is possible to concluded that wood vinegar may be used for the prevention of mold fungi.
\end{abstract}

Keywords: Antifungal, Microfungi, Wood vinegar, In-vitro.

\section{Giriş}

Buğday, tarım ürünleri içerisinde özel bir öneme sahip olup, yüzyıllardır her toplumda beslenmenin temeli olmuştur [1]. Hasat öncesi ile sonrasında, tarımsal ürünlerde toprak ve yaprak patojenleri, viral

\footnotetext{
* Sorumlu yazar: ibrahimkoc47@gmail.com

Geliş Tarihi: 22.05.2018, Kabul Tarihi: 05.11.2018
} 
mikroorganizmalar, böcekler ve küflerin etkisinden ötürü ürün kaybı ve bozulmalar oluşmaktadır [2]. Tarla küfleri ürüne bulaşarak üründe çürüme ve toksin oluşumuna sebep olmaktadır [3].

Tarımsal faaliyetlerde, bitkileri toprak kökenli patojenlerden korumak için kullanılan fungisitlerin, toprak ekolojisi üzerindeki yan etkileri hakkında bilgi eksikliği vardır [4]. Sentetik pestisitlerin yoğun kullanımından dolayı ortaya çıkan problemler, alternatif yöntemlerin ve doğal pestisitlerin aranmasını zorunlu hale getirmiştir [5]. Yin [6] çalışmasında Tsuzuki ve ark. (1989)'a atfen odun sirkesi (OS)' nin, uzun zamandan beri doğal organik pestisit olarak kullanıldığını ifade etmiştir. OS, karbonizasyon işlemlerinin bir yan ürünü olarak üretilmekte olup Neanderthal zamanında kullanıldığı bulunmuştur [7]. Kim vd. [8] çalışmalarında Jang'a hitaben, OS'un \%80- 90'1 su, \%1020 'sinin 200'den fazla organik birleşik ile ana kısmının asetik asit'in oluşturduğunu, son zamanlardaki yıllık üretiminin 14.000 ton civarında olduğunu ifade etmiştir. OS, organik fungisit olarak kullanılmaktadır [9]. OS, su ve topraktaki hedef olmayan organizmalara karşı toksik ya da hafif toksiktir [10]. OS, organik tarım için iyi bir kaynak olup Japonyada tarım ve günlük hayatta geniş bir şekilde kullanılmaktadır [11]. Baimark vd. [12] OS'un güçlü fenolik bileşikler içermesinden dolayı, PDA besiyerindeki fungusun büyümesini engellediğini (Penicillium griseofulvum) bulmuşlardır. Namlı vd. [13] in-vitro şartlarda yaptıkları çalışmada, Cercospora beticola gelişiminin $\% 0.5 \mathrm{~mL}$ OS uygulaması haricinde tamamen engellendiğini tespit etmişlerdir. Omulo vd. [14] OS'un karekterizasyonu göz önüne alındığında fungisit potansiyeli gösterdiğini bildirmişlerdir. Koç vd.[15] OS'un, A. niger ve $P$. digitatum'un misel gelişimlerini engellediği ve hastalık etmenlerine karşı denenmesinin faydalı olabileceğini bildirmişlerdir.

$\mathrm{Bu}$ çalışmadaki amaç, buğday agro-ekosisteminden izole edilen Aspergillus niger ve Penicillium digitatum küf etmenlerine karşı findık kabuklarından elde edilen odun sirkesinin in-vitro şartlarında antifungal etkisini tespit etmektir.

\section{Materyal ve Metot}

\subsection{Materyal}

Denemede Aspergillus niger ve Penicillium digitatum küf etmenleri kullanılmış olup Muş ili BERCE Alparslan Tarım İşletmesinin buğday agro-ekosistemindeki topraktan izole edilmiştir. Odun sirkesi (OS); TÜBİTAK TEYDEB desteği kapsamında findık kabuklarından gazlaştırma makinesi ile biyokömür ve OS ürünlerini geliştiren bir firmadan elde edilmiştir [13]. Mikroorganizmaların çoğaltılmasında ve antifungal etkinin belirlenmesinde, Patates Dekstroz Agar (MERCK) besi ortamı kullanılmıştır.

\subsection{Metot}

\subsubsection{Antifungal aktivite tespiti}

OS'un saf su ile seyreltilmiş $\% 1, \% 3, \% 5, \% 7$ ve $\% 10 \mathrm{~mL}$ 'lik konsantrasyonları, otoklavda $121{ }^{\circ} \mathrm{C}$ 'de 15 dakika sterilize edilen ve $45-50{ }^{\circ} \mathrm{C}^{\prime}$ ye kadar soğutulan PDA besi ortamlarına dahil edilmiştir. $39 \mathrm{gr} / \mathrm{L}$ oranında hazırlanan PDA besi ortamında $25^{\circ} \mathrm{C}$ 'de 7-10 gün geliştirilen stok patojen kültürlerinin büyümenin devam ettiği uç kısımlarından $5 \mathrm{~mm}$ çaplı mantar delici ile diskler alınarak, oda şartlarında OS ilaveli $90 \mathrm{~mm}$ büyüklüğündeki petrilerde yer alan PDA besi ortamına ekimi yapılmıştır.

Mikrofungus kültürleri inokulasyondan sonra $24 \pm 1{ }^{\circ} \mathrm{C}$ 'de 7 gün karanlık koşullarda inkübasyona bırakılmıştır. Kontrol olarak ise funguslar sadece PDA içeren petri kaplarına ekimi yapılmıştır. İnokulasyondan sonra petrilerin etrafı parafilm ile kapatılmış ve 7 gün sonra mikrofungusların miselyum çapı ölçülerek kaydedilmiştir [16]. Çalışma, Tesadüf Parselleri Deneme Deseninde 3 tekerrürlü olarak yürütülmüştür. Miselyum gelişmesi engelleme yüzdesi aşağıdaki formül yardımıyla hesaplanmıştır [17]. GI $(\%)=\mathrm{dc}-\mathrm{dt} / \mathrm{dc} \times 100$

$\mathrm{GI}=$ Miselyum gelişimi engelleme oranı $(\%) ; \mathrm{dc}=$ Kontroldeki miselyum gelişimi $(\mathrm{mm}) ; \mathrm{dt}=$ Uygulamadaki miselyum gelişimi $(\mathrm{mm})$. 


\subsection{2. İstatistiksel Analiz}

Çalışma sonucunda elde edilen veri setinin istatistik analizinde Tek Yönlü Varyans Analizi (One-way ANOVA) tekniğinden, farklı doz odun sirkesi uygulamalarının kontrol grubu ile olan farklarının istatistiksel olarak önemli olma durumlarının belirlenmesi amacı için Dunnet Farklı Grupları Belirleme Testinden yararlanılmıştır. İstatistik analizlerin yapılmasında Minitab (Ver. 17) istatistik paket programı kullanılmıştır [18].

\section{Bulgular ve Tartışma}

Aspergillus niger'e yapılan antimikrobiyal madde testinde, misel gelişiminin ortalama olarak en az \% $10 \mathrm{~mL}$ OS'de $(9.33 \mathrm{~mm})$ ve en çok kontrolde $(27.92 \mathrm{~mm})$, $P$. digitatum'a ise misel gelişiminin ortalama olarak en az \% $10 \mathrm{~mL}$ OS' de $(7.17 \mathrm{~mm})$ ve en çok kontrolde $(34.17 \mathrm{~mm}$ ) olduğu görülmüsştür (Tablo 1). Gerek $A$. niger ve gerekse $P$. digitatum 'un büyüme parametreleri bakımından yapılan Varyans analizleri sonucunda dikkate alınan söz konusu parametreler bakımından dikkate alınan dozlar arasında istatistiksel olarak önemli farkların bulunduğu $(\mathrm{P}=0.000)$ görülmüştür. Hangi dozların kontrol grubu ile olan farklarının istatistiksel olarak önemli olduklarının belirlenmesi amacıyla yapılan Dunnett testi sonucunda her iki türde de $\% 1 \mathrm{~mL}$ OS dozu hariç, kontrol grubu ile dozlar arasında istatistiksel olarak önemli farkların bulunduğu sonucuna varılmıştır (Tablo 1).

Tablo 1. Koloni çapı bakımından tanıtıcı istatistikler ve Dunnet Farklı Grupları Belirleme Testi sonuçları

\begin{tabular}{clccc}
\hline Tür adı & Uygulama & $\bar{X} \mp S_{\bar{X}}$ & $\begin{array}{c}\text { Koloni çapı (mm) } \\
\text { Minimum }\end{array}$ & $\begin{array}{c}\text { Koloni çapı (mm) } \\
\text { Maksimum }\end{array}$ \\
\hline \multirow{4}{*}{ A. niger } & OS $\% 1 \mathrm{~mL}$ & $25.83 \pm 0.51 \mathrm{AB}$ & 25.00 & 26.75 \\
& OS $\% 3 \mathrm{~mL}$ & $24.75 \pm 0.29 \mathrm{~B}$ & 24.25 & 25.25 \\
& OS $\% 5 \mathrm{~mL}$ & $18.92 \pm 0.44 \mathrm{C}$ & 18.25 & 19.75 \\
& OS $\% 7 \mathrm{~mL}$ & $12.92 \pm 0.96 \mathrm{D}$ & 11.00 & 14.00 \\
& OS $\% 10 \mathrm{~mL}$ & $9.33 \pm 0.58 \mathrm{E}$ & 8.25 & 10.25 \\
& Kontrol & $27.92 \pm 0.42 \mathrm{~A}$ & 27.50 & 28.75 \\
P. digitatum & OS $\% 1 \mathrm{~mL}$ & $33.75 \pm 0.14 \mathrm{~A}$ & 33.50 & 34.00 \\
& OS $\% 3 \mathrm{~mL}$ & $31.58 \pm 0.22 \mathrm{~B}$ & 31.25 & 32.00 \\
& OS $\% 5 \mathrm{~mL}$ & $20.08 \pm 0.44 \mathrm{C}$ & 19.25 & 20.75 \\
& OS $\% 10 \mathrm{~mL}$ & $15.42 \pm 0.17 \mathrm{D}$ & 15.25 & 15.75 \\
& Kontrol & $3.17 \pm 0.30 \mathrm{E}$ & 6.75 & 7.75 \\
\hline \multirow{5}{*}{. } & $34.17 \pm 0.22 \mathrm{~A}$ & 33.75 & 34.50 \\
\hline
\end{tabular}

*Aynı türde farklı harflerle gösterilen dozlar arasındaki farklar önemlidir $(\mathrm{P} \leq 0.05)$.

Bu çalş̧mada kullanılan OS'un, antifungal etkisinin olduğu ve artan dozlarda bu etkininde paralel olarak arttığı bulunmuştur. Bu çalışmadan elde edilen sonuçlarla örtüşen çalışmalardan; Chalermsan ve Peerapan [19] elde ettikleri OS'un organik tarımda fungisit ve bakterisit olarak kullanabileceğini dile getirmişlerdir. Ayrıca Baimark vd. [12], Baimark ve Niamsa [20] Penicillium griseofulvum'a karşı gerek kullandıkları ham OS'un ve gerekse fındık kabuklarından elde ettikleri OS'un en etkili antifungal maddeler olduğunu bulmuşlardır. Bir başka çalışmada; Oramahi vd. [21] Aspergillus niger'in büyümesinin artan dozlardaki sirkeye karşı azaldığını ve bu durumun fenol ve asetik asit bileşiklerden kaynaklanabileceğini ifade etmektedirler. Velmurugan [22] Ophiostoma polonicum, $O$. ips, $O$. flexuosum, $O$. narcissi ve $O$. tetropii mantarlarına karşı kullandıkları nötralize edilmiş OS'un \%2.5 mL'den fazlasının güçlü antifungal etki gösterdiğini bulmuşlardır. Ayrıca yapılan başka çalışmalarda da OS'un antifungal etki gösterdikleri yönünde bulgular vardır [13, 15, 23, 24, 25]. Bu çalışmaların yanı sıra, Rabbi vd. [26] deneylerinde kullandıkları OS'un iki çeşidinin A. niger, A. flavus ve Fusarium spp.'e karşı etkili olduğu belirtmişler ve elde edilen bulgularla örtüştügü ancak Trichoderma spp.'nin her iki OS'a karşı direnç gösterdiğini ifade etmişlerdir [26]. Bu çalışmada elde edilen sonucun, Baimark ve Niamsa [20] ile Oramahi vd. [21]'nin bildirdiği üzere OS'un içerdiği fenolik bileşiklerden kaynaklanabileceği düşünülmektedir. Ancak ulaşılan sonuçtan farklı olarak Lee vd. [27] 
Tyromyces palustris ve Coriolus versicolor'a karşı yaptıkları çalışmada; OS'un fungusların büyümesini inhibe etmediğini ifade etmişlerdir.

\section{Sonuç ve Öneriler}

Sonuç olarak; fındık kabuklarından elde edilen odun sirkesinin, A. niger ve $P$. digitatum'un misel gelişimlerini engellediği tespit edilmiş olup, bu sirkenin küf etmenlerine karşı denenmesinin faydalı olabileceği düşünülmektedir.

\section{Kaynaklar}

[1] Arısoy H., Oğuz C. 2005. Tarimsal Araştırma Enstitüleri Tarafından Yeni Geliştirilen Buğday Çeşitlerinin Tarım İşletmelerinde Kullanım Düzeyi ve Geleneksel Çeşitler ile Karşılaştırmalı EkonomikAnalizi - Konya İli Örneği. http://www.tepge.gov.tr/dosyalar/yayinlar/83c3938d2e15467289823d9eb23a05b1.pdf. Tarımsal Ekonomi Araştırma Enstitüsü Yayınları, No: 130, Ankara. (Erişim Tarihi: 18.11.2015).

[2] İmamoğlu Ö. 2011. Biyokontrolde Doğal Ürünlerin Kullanılması; Kitosan, Türk Hijyen ve Deneysel Biyoloji Dergisi, 68 (4): 215-22.

[3] Aydoğdu H. 2016. Edirne İlinde Hasat Sonrası Depolanmış Buğdaylar Üzerinde Taşınan Mikrofungusların İzolasyon ve İdentifikasyonu, Akademik Gida, 14 (4): 362-367.

[4] Chen S., Edwards C.A., Subler S. 2001. Effects of the Fungicides Benomyl, Captan and Chlorothalonil on Soil Microbial Activity and Nitrogen Dynamics in Laboratory Incubations, Soil Biology and Biochemistry, 33 (14): 1971-1980.

[5] Erdoğan P., Toros S. 2005. Melia azaderach L. (Meliaceae) Ekstraktlarının Patates Böceği [Leptinotarsa decemlineata Say (Col.:Chrysomelidae)] Larvalarının Gelişimi Üzerine Etkisi, Bitki Koruma Bülteni, 45 (1-4): 99-118.

[6] Yin A.L. 2008. Isolation and Characterization of Antioxidant Compounds from Pyroligneous Acid of Rhizophora Apiculata (Thesis Doctor of Philosophy). Sains University, Malaysia.

[7] Tiilikkala K., Fagernäs L., Tiilikkala J. 2010. History and Use of Wood Pyrolysis Liquids as Biocide and Plant Protection Product, The Open Agriculture Journal, 4 (1): 111-118.

[8] Kim D.H., Seo H.E., Lee S., Lee K. 2008. Effects of Wood Vinegar Mixted with Insecticides on the Mortalities of Nilaparvata lugens and Laodelphax striatellus (Homoptera: Delphacidae), Animal Cells and Systems, 12 (1): 47-52.

[9] Jothityangkoon D., Koolachart R., Wanapat S., Wongkaew S., Jogloy S. 2008. Using Wood Vinegar in Enhancing Peanut Yield and in Controlling the Contamination of Aflatoxin Producing Fungus, International Crop Science, 4: 253-253.

[10] Hagner M. 2013. Potential of the Slow Pyrolysis Products Birch Tar Oil, Wood Vinegar and Biochar in Sustainable Plant Protection-Pesticidal Effects. Soil İmprovement and Environmental Risks (Thesis), Department of Environmental Sciences Faculty of Biological and Environmental Sciences University of Helsinki, Finland.

[11] Mu J., Uehara T., Furuno T. 2003. Effect of Bamboo Vinegar on Regulation of Germination and Radicle Growth of Seed Plants, Journal of Wood Science, 49 (3): 262-270.

[12] Baimark Y., Threeprom J., Dumrongchai N., Srisuwan Y., Kotsaeng N. 2008. Utilization of Wood Vinegars as Sustainable Coagulating and Antifungal Agents in the Production of Naturel Rubber Sheets, Journel of Environmental Science and Technology, 1 (4): 157-163.

[13] Namlı A., Akça M.O., Turgay E.B., Soba M.R. 2014. Odun Sirkesinin Tarımsal Kullanım Potansiyelinin Araştırılması, Toprak Su Dergisi, 3 (1): 44-52.

[14] Omulo G., Willett S., Seay J., Banadda N., Kabenge I., Zziwa A., Kiggundu N. 2017. Characterization of Slow Pyrolysis Wood Vinegar and Tar from Banana Wastes Biomass as Potential Organic Pesticides, Journal of Sustainable Development, 10 (3): 81-92.

[15] Koç İ., Yardım E.N., Yıldız Ş. 2017. In Vitro Şartlarında Küf Etmenlerine Karşı Tavuk Gübresinden Elde Edilmiş Odun Sirkesinin Antifungal Etkisi, Yüzüncü Yıl Üniversitesi Tarım Bilimleri Dergisi, 27 (4): 516-520.

[16] Benjilali B., Tantadui-Elaraki A., Ayadi A., Ihlal M. 1984. Method to Study Antimicrobial Effects 
of Essential Oils: Application to the Antifungal Activity of Six Moroccan Essences, Journal of Food Protection, 47: 748-752.

[17] Daouk K.D., Dagher M.S., Sattout J.E. 1995. Antifungal Activity of the Essential Oil of Origanum syriacum L, Journal of Food Protection, 58: 1147-1149.

[18] Winer B.J., Brown D.R., Michels K.M. 1971. Statistical Principles in Experimental Design, Vol. 2, McGraw-Hill, New York.

[19] Chalermsan Y., Peerapan S. 2009. Wood Vinegar: By-Product from Rural Charcoal Kiln and its Role in Plant Protection, Asian Journal of Food and Agro-Industry, 189-195.

[20] Baimark Y., Niamsa Y. 2009. Study on Wood Vinegars for Use as Coagulating and Antifungal Agents on the Production of Natural Rubber Sheets, Biomass and Bioenergy, 33: 994-998.

[21] Oramahi H.A., Diba F., Wahdina. 2009. Components and Antifungal Efficiency of Wood Vinegar from Wood Wastes and Oil Palm Empty Fruit Bunch, The First International Symposium of Indonesian Wood Research Society, 2nd-3rd November, West Kalimantan, Indonesia, 91.

[22] Velmurugan N., Han S.S., Lee Y.S. 2009. Antifungal Activity of Neutralized Wood Vinegar with Water Extracts of Pinus densiflora and Quercus serrata Saw Dusts, International Journal of Environmental Research, 3 (2): 167-176.

[23] Ibrahim D., Kassim J., Sheh-Hong L., Rusli W. 2013. Efficacy of Pyroligneous Acid from Rhizophora apiculata on Pathogenic Candida albicans, Journal of Applied Pharmaceutical Science, 3 (7): 7-13.

[24] Oramahi H.A., Yoshimura T. 2013. Antifungal and Antitermitic Activities of Wood Vinegar from Vitex pubescens vahl, Journal of Wood Science, 59 (4): 344-350.

[25] Saberi M., Askary H., Sarpeleh A., Hosseini A. 2013. Wood Vinegar as a Biological Product for Managing Fusarium oxysporum f. sp. radicis-cucumerinum, Canadian Journal of Plant Protection (CJPP), 1 (4).

[26] Rabbi M.A., Akhter A., Khan M., Kadri H.J., Maitra B., Khatun M.H. 2017. Chemical Composition and Antifungal Activity of Sugarcane Bagasse and Banana Stem Based Wood Vinegar, Journal of Chemical, Biological and Physical Sciences, 7 (4): 898-904.

[27] Lee D.H., Lee T.S., Kang C.H., Kim J.K., Kang H.Y. 1992. Aptitude Of Wood Vinegar As An Alternative Wood Preservative. http://agris.fao.org/agrissearch/searchIndex.do?query=Aptitude+of+Wood+Vinegar+as+an+Alternative+Wood+Preserv ative. Res. Rep. For. Res. Inst. No.45, Forestry Research Institute, Seoul, Korea. (Erişim Tarihi: 22.02.2016). 